\title{
Routine Data Analyses for Estimating the Caries Treatment Experience of Children
}

\author{
Michael Raedel $^{\mathrm{a}}$ Yvonne Wagner $^{\mathrm{b}, c}$ Heinz-Werner Priess ${ }^{\mathrm{d}}$ Stefanie Samietz ${ }^{\mathrm{e}}$ \\ Steffen Bohm ${ }^{d}$ Michael H. Walter ${ }^{\text {a }}$ \\ aProsthodontics, Carl Gustav Carus Faculty of Medicine, TU Dresden, Dresden, Germany; ${ }^{b}$ Department of \\ Orthodontics, Pediatric and Preventive Dentistry, Jena University Hospital, Jena, Germany; 'Training Centre of the \\ Dental Association Baden-Württemberg (ZFZ Stuttgart), Stuttgart, Germany; ${ }^{d}$ AGENON GmbH, Berlin, Germany; \\ eDepartment of Prosthodontics, Centre for Oral Health, University Medicine Greifswald, Greifswald, Germany
}

\section{Keywords}

Dental caries · Children · Routine data · Caries experience ·

Treatment experience

\begin{abstract}
Oral health surveys are considered the gold standard for assessing the caries experience of children. Analyses of routine data offer additional opportunities not yet fully explored. This study aimed at estimating the caries treatment experience by mining an insurance claims database. Comprehensive claims data sets were extracted from the data warehouse of a major health insurance company (BARMER, Germany). A surrogate variable for caries experience was formed that reflected the proportion of children without any former potentially caries-related treatment (filling, root canal treatment, and extraction) at ages from 1 to 14 years. The statistical calculations were based on Kaplan-Meier survival analyses. The evaluation for the permanent dentition comprised $N=593,330$ children at 6 years and $N=114,568$ at 12 years. At 12 years of age, $66.8 \%$ had not yet experienced potentially caries-related treatments. This value hints at a significantly higher caries experience at 12 years compared to available epidemiological data. For the deciduous dentition,
\end{abstract}

the respective rates were $74.0 \%$ at 6 years and $45.8 \%$ at 10 years. Although various sources of bias have to be taken into account, the potential of routine data mining is evident. The approach is supplemental to oral health surveys. It can be useful in coming closer to reality when estimating the caries experience of children. From our results, we conclude that the oral health of up to 14-year-olds in Germany remains in urgent need of improvement.

(C) 2021 The Author(s)

Published by S. Karger AG, Basel

\section{Introduction}

Caries is still the most relevant oral disease. It is unevenly distributed and preventable [Pitts et al., 2017]. The Global Burden of Disease Study 2017 estimated that worldwide caries affects 2.3 billion people in the permanent dentition and $>530$ million children in the primary dentition [Spencer and Geleijnse, 2018]. Many countries like Germany, the USA, and the UK regularly evaluate and publish epidemiological data on important oral health indicators, among them caries prevalence and caries experience for certain age-groups [Steele et al., 2012; Jordan et al., 2014; Dye et al., 2019]. Management and
C 2021 The Author(s).

Published by S. Karger AG, Basel

This article is licensed under the Creative Commons Attribution 4.0 International License (CC BY) (http://www.karger.com/Services/ OpenAccessLicense). Usage, derivative works and distribution are permitted provided that proper credit is given to the author and the original publisher.
Correspondence to:

Michael Raedel, michael.raedel@uniklinikum-dresden.de 
financial support of health-care systems, prevention programs, and education strategies might be strongly influenced by these data. They must come as close as possible to reality, because politicians and decision makers rely on them [Kassebaum et al., 2015]. However, caries diagnosis criteria are complex. Therefore, reported data should be as transparent and comprehensive as possible.

In international epidemiological studies, caries experience is still mostly described using the DMF-index which has also been questioned [Broadbent and Thomson, 2005; Castro et al., 2018; Frencken et al., 2020]. Oral health surveys using the DMF-index might underestimate the caries experience especially in children because non-cavitated lesions are not counted [Alves et al., 2018]. Diagnostic thresholds strongly influence the reported levels of caries and the rates of children without caries experience [Pitts and Fyffe, 1988; Wang et al., 2021]. In the Children's Dental Health Survey (CDHS 2013) in England, Wales, and Northern Ireland, only $35.15 \%$ of 12 -year-olds were sound (regarding caries) when counting both clinical decay of at least visual enamel caries and obvious decay but excluding subclinical decay and lesions seen only on radiographs [Wang et al., 2021]. Caries detection systems alternative to the DMF-index have been introduced such as the International Caries Detection and Assessment System (ICDAS) and the caries assessment spectrum and treatment. These instruments provide information on lesion severity and have special characteristics and application fields with caries assessment spectrum and treatment being a potentially favorable tool for epidemiological studies [Castro et al., 2018; Frencken et al., 2020]. Despite the established weaknesses, the DMF-index remains a valid instrument that facilitates international comparisons and is easy to handle. Current data show a continuous caries decline in 12-year-olds in Germany indicated by an increasing proportion of children with DMFT $=0$ which was 79\% in 2016 [Splieth et al., 2019]. For the primary dentition, only minor improvements over 10-15 years until 2016 were reported founded on the DMFT [Santamaria et al., 2019].

Based on national studies, the World Health Organization (WHO) runs an oral health database (https://www. who.int/oral_health/databases/en/). It also provides a collection of standardized basic methods for oral health surveys to ensure international comparability due to simple and effective standardized clinical evaluations [World Health Organization, 2013]. A potential weakness of representative oral health surveys lies in the impact of nonresponders. It can be hypothesized that among the nonresponders, children with a higher caries experience are overrepresented leading to an underestimation of caries experience in case of lacking appropriate adjustments.

The aim of this study was to measure the caries treatment experience of children by routine data analysis. Thereby, the potential of routine data analyses for supplementing epidemiological studies should be estimated.

\section{Materials and Methods}

For a number of publications, the authors extracted and analyzed data from a major health insurance company (BARMER, Germany). Data and methods proved to be suitable to describe numerous outcomes relevant to dental care [Raedel et al., 2017, 2019, 2020].

The study design was approved by the responsible local ethics board (EK 288072015). Comprehensive claims data sets were extracted from the data warehouse of the insurance company including sociodemographic characteristics, treated teeth, fee codes, and treatment (billing) dates. Anonymized data of insured children were used for uninterrupted follow-up over the relevant time span. Respective data were available for a 9-year period from January 1 , 2010, until December 31, 2018. Date of birth and gender were known for all individuals. Additional clinical information such as findings and diagnoses were not available.

A surrogate variable for caries experience was formed that expressed the proportion of children without a preceding potentially caries-related treatment. These index treatments counted as potentially caries-related treatments were fillings, root canal treatments and extractions at ages from 1 to 14 years. Thus, we actually measured the billed caries treatment experience. The date of birth had to be January 1, 2004, or later for the separate analysis of the permanent dentition and January 1, 2008, or later for the analyses of the deciduous dentition and all teeth from birth. For data protection reasons, we had no direct access to dates of birth. Instead, we used the dates of joining the insurance as reference for age. This applied to the vast majority of individuals. For children who did not join the insurance in their year of birth, we took the middle of the birth year (July 1) as replacement. During the first year after birth we assumed no cariesrelated treatment. To expand the observation period to 10 years, we also included the 2008 birth cohort although we had no treatment data for the first and the second year. This leads to a minimal underestimation of the caries treatment experience most probably distinctly under $0.1 \%$ which we considered negligible. All eligible children were included for the period of their uninterrupted membership in the insurance. Kaplan-Meier survival analyses for the outcome "potentially caries-related treatment" were used for statistical evaluation. Thus, the first index treatment was counted as target event. Regular extractions of deciduous teeth did not count as potentially cariesrelated treatment. These regular extractions were defined as extractions of deciduous incisors from 6 years on and extractions of other deciduous teeth starting from 9 years on. Symmetric extractions of premolars at the same time did not count as potentially caries-related treatments because they were considered as being conducted for orthodontic reasons. Because of the high number of included individuals and the recording of index treatments with exact dates, the Kaplan-Meier curves did not show the typical stepped shape in the graphical depictions. We used the statistical software R (R Core 


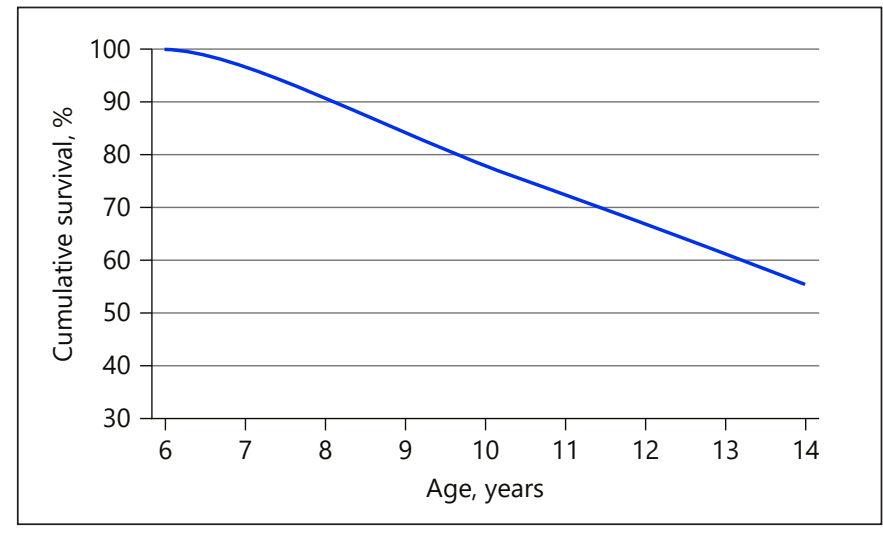

Fig. 1. Survival function related to potentially caries-related treatments (filling, root canal treatment, and extraction) on permanent teeth from 6 to 14 years of age.

Team: "R (2019): A language and environment for statistical computing", R Foundation for Statistical Computing, Vienna, Austria, https://www.R-project.org/) with a package for survival analyses (A Package for Survival Analysis in R, R package version 3.2-10, https:// CRAN.R-project.org/package=survival).

\section{Results}

The survival analysis for the permanent dentition starting at 6 years of age comprised $N=593,330$ children (Table 1). At 10 years of age, $78.0 \%$ of the children were still without a potentially caries-related treatment. This rate decreased to $66.8 \%$ at the age of 12 years and $55.4 \%$ at the age of 14 years when only $N=31,225$ were still under risk. As expected, the respective Kaplan-Meier curve showed a continuous decrease becoming close to linear from the age of 7 years on (Fig. 1).

The survival analysis for all permanent and deciduous teeth started at 1 year and comprised $N=613,927$ cases (Table 2). At 6 years of age, $72.3 \%$ of the children had not yet experienced a potentially caries-related treatment. At 10 years of age, $37.8 \%$ of the children were still without any potentially caries-related treatment. When only focusing on deciduous teeth, the rates were $74.0 \%$ at 6 years and $45.8 \%$ at 10 years. The minor discrepancies between deciduous teeth and all teeth with slightly lower survival rates for all teeth were not plausible under 6 years of age. We suppose a low number of misclassifications (permanent instead of deciduous teeth). We decided against a correction because of the insubstantial magnitude of error. The respective Kaplan-Meier curves were slightly flattening beginning with 7 years in deciduous teeth and 8 years when including all teeth (Fig. 2).
Table 1. Cumulative survival rates representing children without a potentially caries-related treatment (filling, root canal treatment, and extraction) on permanent teeth and age-related numbers of remaining children under risk

\begin{tabular}{lll}
\hline $\begin{array}{l}\text { Age, } \\
\text { years }\end{array}$ & $\begin{array}{l}\text { Children } \\
\text { under risk, } \\
n\end{array}$ & $\begin{array}{l}\text { Rate of children without a } \\
\text { potentially caries-related } \\
\text { treatment (cumulative } \\
\text { survival rate), \% }\end{array}$ \\
\hline 6 & 593,330 & \\
7 & 492,976 & 96.8 \\
8 & 395,791 & 90.7 \\
9 & 307,599 & 84.0 \\
10 & 233,404 & 78.0 \\
11 & 169,575 & 72.4 \\
12 & 114,568 & 66.8 \\
13 & 69,124 & 61.1 \\
14 & 31,225 & 55.4 \\
\hline
\end{tabular}

Table 2. Cumulative survival rates representing children without a potentially caries-related treatment (filling, root canal treatment, and extraction) in deciduous and permanent teeth together (all teeth) and in deciduous teeth separately

\begin{tabular}{llll}
\hline $\begin{array}{l}\text { Age, } \\
\text { years }\end{array}$ & $\begin{array}{l}\text { Children } \\
\text { under risk, } \\
n\end{array}$ & $\begin{array}{l}\text { Rate of children without a } \\
\text { potentially caries-related treatment } \\
\text { (cumulative survival rate), \% }\end{array}$ \\
\cline { 3 - 4 } & & on all teeth & $\begin{array}{l}\text { on deciduous } \\
\text { teeth only }\end{array}$ \\
\hline 1 & & & 100.0 \\
2 & 613,927 & 100.0 & 99.8 \\
3 & 598,645 & 99.7 & 98.1 \\
4 & 496,360 & 97.8 & 92.6 \\
5 & 394,626 & 92.2 & 83.6 \\
6 & 293,348 & 82.8 & 74.0 \\
7 & 206,097 & 72.3 & 65.0 \\
8 & 137,414 & 62.2 & 57.3 \\
9 & 84,342 & 52.3 & 50.8 \\
10 & 46,035 & 44.0 & 45.8 \\
\hline
\end{tabular}

Age-related numbers of remaining children under risk.

\section{Discussion}

This is the first attempt to analyze the caries treatment experience of children based on a very large sample of claims data. The approach proved to be practical. Our results show that only two-thirds of the 12-year-old children were without experience of potentially caries-related treatments on their permanent teeth. The analysis of the 


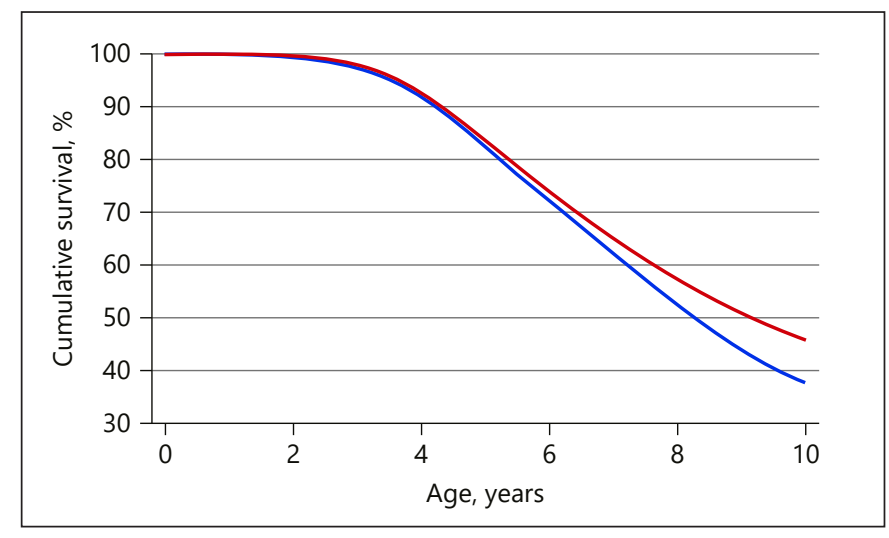

Fig. 2. Survival functions related to potentially caries-related treatments (filling, root canal treatment, and extraction) on all teeth (blue) and only deciduous teeth (red) from 1 to 10 years of age.

deciduous and the permanent dentition together showed that less than half of the 10-year-old children were without experience of potentially caries-related treatments. There are a number of sources of bias possibly leading to a tendency towards overestimation of the caries experience in the permanent dentition. However, also sources of bias toward underestimation exist. In the deciduous dentition, the only bias of higher relevance is untreated caries in the absence of further caries-related treatments leading to a virtually certain underestimation of the caries experience. In summary, we value our results as a sign for an oral health of up to 14-year-olds still being in urgent need of improvement.

A number of regional and local studies provided data for the deciduous dentition pointing in the same direction as our results [Wagner et al., 2014, 2020; Santamaria et al., 2015, 2019; Weusmann et al., 2015; Wagner and Heinrich-Weltzien, 2017]. In Germany, the caries reductions in the permanent dentition of children and adolescents started with a delay and are still continuing [Pieper and Schulte, 2004; Jordan et al., 2016]. Although clear declines in 12-year-olds have been reported [Splieth et al., 2019], we are still facing increasing caries levels with age and a high prevalence and relevance of caries in adults [Bernabe and Sheiham, 2014].

Basically, routine data allow easy determination of the rate of individuals who experienced (invasive) treatments which is on its own a supplemental and valuable oral health indicator. When translating this rate into an estimation of the rate of individuals with caries experience, it is getting more complicated and a number of potential sources of bias have to be taken into account. Yet, we consider this approach valuable and justified.

Routine Data Analyses for Estimating Children's Caries Treatment Experience
The statistical approach with Kaplan-Meier survival analyses for children with different years of birth leads to averaging effects. This has to be taken into account when comparing the results with other studies. An advantage of the Kaplan-Meier analyses is the output of caries experience rates at different ages and the related information on the course of the disease over the entire childhood. Caries diagnosis criteria and dentists ' attitudes towards caries treatment are among the most significant influencing variables in assessing caries experience. A systematic review and meta-analysis focused on restorative thresholds for carious lesions [Innes and Schwendicke, 2017]. The authors found an obvious gap between evidence and dental practice. A considerable proportion of dentists and dental therapists still gave invasive treatments as their preference in lesions where contemporary recommendations favor less invasive approaches, for example, lesions without dentine involvement. From these findings, it can be concluded that dentists' attitudes and preferences are a significant source of uncertainty regarding the caries experience derived from existing restorations. The above cited review showed considerable differences between countries that may be explained by differences in education and health service systems. Supposedly, a significant number of fillings in claims data and epidemiological studies were placed in lesions that would not be counted as caries according to the WHO criteria. The resulting bias leading to an overestimation of the caries experience applies to both routine data analyses and epidemiological studies.

In our study, we focused on the assessment of children without caries experience because this rate can be approximately determined with claims data. Missing caries experience expressed by a DMFT value 0 cannot be assessed with claims data. Instead, the rate of children without experience of potentially caries-related treatments can be used as a surrogate variable.

Going into more detail, we expect a minor overall overestimation of the caries experience in claims data analyses (Table 3). Although claims data offer various advantages, there are numerous inherent limitations that are well known [Funk and Landi, 2014]. Systematic errors prevail. The sources of bias discussed in the following paragraphs only become relevant in the absence of further caries-related treatments.

Because of lacking diagnoses, untreated caries remains invisible in most routine data sets. However, for our analysis a rough estimation was possible. Based on published data of a nationwide survey [Jordan et al., 2016], we estimate the overall underestimation of the caries experience 
Table 3. Judgment of internal validity

\begin{tabular}{|c|c|c|c|c|}
\hline Study & Source of bias & $\begin{array}{l}\text { Direction of bias (relative to } \\
\text { caries experience) }\end{array}$ & $\begin{array}{l}\text { Magnitude } \\
\text { of bias }\end{array}$ & Remarks \\
\hline $\begin{array}{l}\text { Routine data } \\
\text { analysis }\end{array}$ & $\begin{array}{l}\text { Untreated caries } \\
\text { Preventive resin restorations counted as caries-related } \\
\text { restorations and caries surrogate } \\
\text { Trauma-related restorations counted as caries surrogate } \\
\text { MIH-related restorations counted as caries surrogate } \\
\text { Erosion-related restorations counted as caries surrogate } \\
\text { Extractions not caused by caries counted as caries surrogate } \\
\text { Coding errors } \\
\text { Overall }\end{array}$ & $\begin{array}{l}\text { Underestimation } \\
\text { Overestimation } \\
\text { Overestimation } \\
\text { Overestimation } \\
\text { Overestimation } \\
\text { Overestimation } \\
\text { Overestimation, underestimation } \\
\text { Overestimation }\end{array}$ & $\begin{array}{l}\text { Moderate } \\
\text { Moderate } \\
\text { Moderate } \\
\text { Weak } \\
\text { Weak } \\
\text { Weak } \\
\text { Weak } \\
\text { Weak }\end{array}$ & $\begin{array}{l}\text { Only relevant in } \\
\text { case of missing } \\
\text { further caries- } \\
\text { related treatments }\end{array}$ \\
\hline $\begin{array}{l}\text { Oral health } \\
\text { survey }\end{array}$ & $\begin{array}{l}\text { Overlooked tooth-colored restoration } \\
\text { Overlooked caries } \\
\text { Caries-related restorations counted as sealants or preventive } \\
\text { resin restorations and vice versa } \\
\text { Caries-related restorations counted as trauma-related and vice } \\
\text { versa } \\
\text { Caries-related restorations counted as MIH-related and vice versa } \\
\text { Caries-related restorations counted as erosion-related and vice } \\
\text { versa } \\
\text { Overall }\end{array}$ & $\begin{array}{l}\text { Underestimation } \\
\text { Underestimation } \\
\text { Underestimation, overestimation } \\
\text { Underestimation, overestimation } \\
\text { Underestimation, overestimation } \\
\text { Underestimation, overestimation }\end{array}$ & $\begin{array}{l}\text { Moderate } \\
\text { Weak } \\
\text { Moderate } \\
\text { Weak } \\
\text { Weak } \\
\text { Weak }\end{array}$ & $\begin{array}{l}\text { Only relevant in the } \\
\text { absence of further } \\
\text { DMFT related } \\
\text { findings. } \\
\text { Magnitudes of bias } \\
\text { influenced by } \\
\text { examination } \\
\text { conditions }\end{array}$ \\
\hline
\end{tabular}

Variable: caries experience of 12-year-olds. Main sources, direction and magnitude of bias. Routine data analysis versus oral health surveys. No claim to completeness. MIH, molar incisor hypomineralization.

in the permanent dentition related to uncounted untreated caries roughly as being at least $5 \%$ when referring to the WHO diagnosis criteria.

There are a number of further sources of misclassifications. In Germany, for preventive resin restorations in small carious lesions without cavitation in dentine, the fee code for restorations (fillings) can be used. In the effective absence of caries with cavitation in dentine, this specific regulation of the German health service system leads to an overestimation of the caries experience when taking the WHO criteria for the definition of caries as a basis [World Health Organization, 2013].

Restorations placed because of non-carious defects caused by trauma, molar incisor hypomineralization and erosion are mostly not identifiable in routine data sets. In the German setting, shares of the trauma-related restorations are not part of the health insurance claims data because they are covered by a different funder. This specific regulation reduces the respective overestimation of the caries experience in our data.

Extractions not caused by caries, for example, because of trauma or orthodontic treatment may be counted as caries-related in routine data analyses. Depending on the data set, the resulting bias can be reduced by adjustments. In the current analyses, we excluded symmetric extrac- tions of permanent premolars that were expected to be mostly conducted for orthodontic reasons.

\section{Comparison of Routine Data Analyses and Oral \\ Health Surveys}

Our findings were the motivation for a general comparison of routine data analyses with oral health surveys regarding internal and external validity (Tables 3,4 ). In our judgments, we basically refer to the assessment of the caries experience through the rate of children without caries experience at different ages. In oral health surveys, we assume a minor overall underestimation of the caries experience in terms of the internal validity. Random errors prevail. The given sources of bias are misclassifications. They become only relevant in the absence of further DMFT relevant findings such as caries, caries-related restorations, and missing teeth. Generally, the examination conditions have an influence on the risks of bias [Mutsvari et al., 2012].

Tooth-colored restorations can be overlooked [Mutsvari et al., 2012], especially when small and with good color match. Caries can also be overlooked, however, probably to a lower extent. Caries-related restorations can be counted as sealants or preventive resin restorations. The uncertainty related to preventive resin res- 
Table 4. Judgment of external validity

\begin{tabular}{|c|c|c|c|c|}
\hline \multirow[t]{2}{*}{ Representativity } & $\begin{array}{l}\text { Sample representative for a small } \\
\text { study population }\end{array}$ & Negative & Representative sample & Positive \\
\hline & $\begin{array}{l}\text { Sample representative for a large } \\
\text { study population (e.g., nationwide } \\
\text { insurance data) }\end{array}$ & $\begin{array}{l}\text { Negative to positive } \\
\text { (depending on } \\
\text { population } \\
\text { characteristics) }\end{array}$ & Nonrepresentative sample & Negative \\
\hline \multirow[t]{2}{*}{ Response/selection } & \multirow{2}{*}{$\begin{array}{l}\text { Very high coverage rate, no } \\
\text { selection }\end{array}$} & \multirow[t]{2}{*}{ Positive } & Low response rate & Negative \\
\hline & & & High response rate & Positive \\
\hline Blinding (subjects) & $\begin{array}{l}\text { Health system data - no direct } \\
\text { connection to subjects }\end{array}$ & Positive & $\begin{array}{l}\text { Subjects are informed about } \\
\text { study aim - healthy subjects } \\
\text { possibly more attracted }\end{array}$ & Negative \\
\hline Statistical adjustments & $\begin{array}{l}\text { Adjustments possible (e.g., of age } \\
\text { and gender) }\end{array}$ & Positive & No nonresponse analysis & Negative \\
\hline Potential replication & Replication easily possible & Positive & Possible, but more difficult & Negative \\
\hline
\end{tabular}

Variable: caries experience of 12 -year-olds. Routine data analysis versus oral health survey. No claim to completeness.

torations has been described above. The current sealant rate in 12 -year-olds was reported to be over $70 \%$ [Jordan et al., 2016]. Probably, the high prevalence of sealants is the most important source of uncertainties in oral health surveys when it comes to the rate of 12 -year-olds without caries experience because of the unknown rate of cases with dentine caries. Caries-related restorations may be counted as trauma-related, molar incisor hypomineralization-related, and erosion-related restorations. By clinical examination, location, shape, and medical history can be used for the identification of restorations not caused by caries although a considerable degree of uncertainty remains. A vice versa misclassification is also possible.

The external validity of routine data analyses in particular depends on sample size and population characteristics. The external validity of oral health surveys is strongly influenced by the sample size, representativity, and response rate (Table 4). Low response rates possibly lead to a significant underestimation of the caries experience because nonresponders might have a considerably higher caries experience. All judgments relative to the internal and external validity are to some extent speculative. When merging the judgments of internal and external validity, we assume tendencies toward overestima- tion of the caries experience in routine data analyses. The degree of overestimation may vary considerably depending on which reference data we are relating them to. When compared with epidemiological data comprising lower caries levels, the assumed overestimation with claims data can even turn into an underestimation. In oral health surveys, the data strongly depend on study design, implementation, and instruments used. With respect to our specific claims data analysis, our hypothesis is that the reality lies somewhere between the routine data results and those of the actual nationwide survey results [Jordan et al., 2016].

Our juxtaposition of routine data analyses and oral health surveys is focusing on 2 completely different approaches for assessing the oral health of children. We attempted to conduct a detailed appraisal of potential strengths and weaknesses. Although derived from the German setting, most aspects are presumably transferrable to other countries. They should be of value when setting up studies and interpreting oral health data from children. When planning studies using routine data, a thorough analysis of possible sources of bias related to the specific local terms and conditions should be conducted. 


\section{Conclusion}

A variety of study designs and instruments with different characteristics and application fields are available for measuring the caries experience of children. They lead to differing results. From the perspective of public health epidemiology, all data are valuable and may complement each other to a valid picture of reality provided that they are originating from well conducted studies.

Routine data analyses are easier, less time consuming, and less expensive than comprehensive oral health surveys. The availability of usable data is growing. Although a number of sources of bias have to be taken into account, the great potential of routine data mining is evident. The most striking advantage is the absence of a nonresponder bias. Routine data analyses are of high interest to all players in the field of public health.

\section{Acknowledgment}

We acknowledge Dr. Ursula Marschall (BARMER, Germany) for her extensive support.

\section{Statement of Ethics}

The study design was approved by the responsible Ethics Committee (EK 288072015).

\section{Conflict of Interest Statement}

Michael Raedel is unregularly acting as a consultant in dentistry matters for the BARMER health insurance company. All other authors have no conflicts of interest to declare.

\section{Funding Sources}

The study was partially supported by the BARMER - a German national health insurance company.

\section{Author Contributions}

Michael Raedel contributed to the manuscript in terms of conceptualization, study design, statistical approach, interpretation, writing, and editing. Yvonne Wagner contributed to the manuscript in terms of conceptualization, study design, interpretation, writing, and editing. Heinz-Werner Priess contributed to the manuscript in terms of study design, data handling, statistics, interpretation, visualization, and writing. Stefanie Samietz contributed to the manuscript in terms of interpretation, writing, and editing. Steffen Bohm contributed to the manuscript in terms of study design, statistics, interpretation, and editing. Michael H. Walter contributed to the manuscript in terms of supervision, conceptualization, study design, interpretation, writing, and editing.

\section{Data Availability Statement}

The datasets generated during and/or analysed during the current study are not publicly available due to data holder restrictions. Preliminary data was published/is available in German language (Rädel M et al. BARMER Zahnreport 2020. Zweiband media GmbH, Berlin: 2020).

\section{References}

Alves LS, Susin C, Damé-Teixeira N, Maltz M. Impact of different detection criteria on caries estimates and risk assessment. Int Dent J. 2018;68(3):144-51.

Bernabe E, Sheiham A. Age, period and cohort trends in caries of permanent teeth in four developed countries. Am J Public Health. 2014; 104:e115-21.

Broadbent JM, Thomson WM. For debate: problems with the DMF index pertinent to dental caries data analysis. Community Dent Oral Epidemiol. 2005;33(6):400-9.

Castro ALS, Vianna MIP, Mendes CMC. Comparison of caries lesion detection methods in epidemiological surveys: CAST, ICDAS and DMF. BMC Oral Health. 2018;18(1):122.

Dye BA, Afful J, Thornton-Evans G, Iafolla T. Overview and quality assurance for the oral health component of the national health and nutrition examination survey (NHANES), 2011-2014. BMC Oral Health. 2019;19(1):95.
Frencken JE, Giacaman RA, Leal SC. An assessment of three contemporary dental caries epidemiological instruments: a critical review. Br Dent J. 2020;228(1):25-31.

Funk MJ, Landi SN. Misclassification in administrative claims data: quantifying the impact on treatment effect estimates. Curr Epidemiol Rep. 2014;1(4):175-85.

Innes NPT, Schwendicke F. Restorative thresholds for carious lesions: systematic review and meta-analysis. J Dent Res. 2017;96(5):501-8.

Jordan AR. Versorgungsfrei? Kariesfrei: IDZStellungnahme Zahnreport. 2020.

Jordan AR, Micheelis W, Cholmakow-Bodechtel C. Fünfte deutsche Mundgesundheits-Studie (DMS V). Köln: Deutscher Zahnärzte Verlag; 2016.

Jordan RA, Bodechtel C, Hertrampf K, Hoffmann T, Kocher T, Nitschke I, et al. The fifth German oral health study (fünfte deutsche Mundgesundheitsstudie, DMS V): rationale, design, and methods. BMC Oral Health. 2014;14:161.
Kassebaum NJ, Bernabé E, Dahiya M, Bhandari B, Murray CJ, Marcenes W. Global burden of untreated caries: a systematic review and metaregression. J Dent Res. 2015;94(5):6508.

Mutsvari T, García-Zattera MJ, Declerck D, Lesaffre E. Dealing with misclassification and missing data when estimating prevalence and incidence of caries experience. Community Dent Oral Epidemiol. 2012;40 Suppl 1:28-35.

Pieper K, Schulte AG. The decline in dental caries among 12-year-old children in Germany between 1994 and 2000. Community Dent Health. 2004;21:199-206.

Pitts NB, Fyffe HE. The effect of varying diagnostic thresholds upon clinical caries data for a low prevalence group. J Dent Res. 1988;67(3): 592-6.

Pitts NB, Zero DT, Marsh PD, Ekstrand K, Weintraub JA, Ramos-Gomez F, et al. Dental caries. Nat Rev Dis Primers. 2017;3:17030.

Raedel/Wagner/Priess/Samietz/Bohm/ Walter 
Raedel M, Hartmann A, Priess HW, Bohm S, Samietz S, Konstantinidis I, et al. Re-interventions after restoring teeth-Mining an insurance database. J Dent. 2017;57:14-9.

Raedel M, Priess HW, Bohm S, Noack B, Wagner Y, Walter MH. Tooth loss after periodontal treatment - mining an insurance database. J Dent. 2019;80:30-5.

Raedel M, Priess HW, Bohm S, Walter MH. Sixyear survival of single crowns: a massive data analysis. J Dent. 2020;101:103459.

Rothman KJ, Greenland S, Lash TL. Modern epidemiology. 3rd ed. Philadelphia: Wolters Kluwer Health/Lippincott Williams \& Wilkins; 2008.

Santamaria RM, Basner R, Schüler E, Splieth CH. Inequalities in dental caries experience among 6-year-old German children after the caries decline. Acta Odontol Scand. 2015;73(4): 285-91.

Santamaria RM, Schmoeckel J, Basner R, Schuler E, Splieth $\mathrm{CH}$. Caries trends in the primary dentition of 6- to 7-year-old schoolchildren in Germany from 1994 to 2016: results from the German national oral health surveys in children. Caries Res. 2019;53:659-66.
Spencer LJ, Geleijnse JM. Global, regional, and national incidence, prevalence, and years lived with disability for 354 diseases and injuries for 195 countries and territories, 19902017: a systematic analysis for the Global Burden of Disease Study 2017. Lancet. 2018;392. 1789-858.

Splieth C, Meyer G. Factors for changes of caries prevalence among adolescents in Germany. Eur J Oral Sci. 1996;104(4 Pt 2):444-51.

Splieth CH, Santamaria RM, Basner R, Schüler E, Schmoeckel J. 40-year longitudinal caries development in German adolescents in the light of new caries measures. Caries Res. 2019; 53(6):609-16.

Steele JG, Treasure ET, O’Sullivan I, Morris J, Murray JJ. Adult dental health survey 2009: transformations in British oral health 19682009. Br Dent J. 2012;213(10):523-7.

Wagner Y, Greiner S, Heinrich-Weltzien R. Evaluation of an oral health promotion program at the time of birth on dental caries in 5-yearold children in Vorarlberg, Austria. Community Dent Oral Epidemiol. 2014;42:160-9.
Wagner Y, Heinrich-Weltzien R. Evaluation of a regional German interdisciplinary oral health programme for children from birth to 5 years of age. Clin Oral Investig. 2017;21(1):225-35.

Wagner Y, Knaup I, Knaup TJ, Jacobs C, Wolf M. Influence of a programme for prevention of early childhood caries on early orthodontic treatment needs. Clin Oral Investig. 2020; 24(12):4313-24.

Wang X, Bernabe E, Pitts N, Zheng S, Gallagher JE. Dental caries thresholds among adolescents in England, Wales, and Northern Ireland, 2013 at 12, and 15 years: implications for epidemiology and clinical care. BMC Oral Health. 2021;21(1):137.

Weusmann J, Mahmoodi B, Azaripour A, Kordsmeyer K, Walter C, Willershausen B. Epidemiological investigation of caries prevalence in first grade school children in RhinelandPalatinate, Germany. Head Face Med. 2015; 11(1):33.

World Health Organization. Oral health surveys: basic methods. 5th ed. Geneva: World Health Organization; 2013. 